\title{
Determination of compression curve of in-situ soil considering soil disturbance
}

\author{
Binbin $\mathrm{Xu}^{1,2,3,4, \mathrm{a}^{*}}$ and Naishou Zhang ${ }^{2, \mathrm{~b}}$ \\ ${ }^{1}$ Tianjin Port Engineering Institute Ltd. of CCCC, Tianjin, China \\ ${ }^{2}$ CCCC First Harbor Engineering Co. Ltd., Tianjin, China \\ ${ }^{3}$ Key Lab. of Geotechnical Engineering of Tianjin, Tianjin, China \\ ${ }^{4}$ Key Lab. of Geotechnical Engineering, Ministry of Communication, Tianjin, China \\ axubinbin@tpei.com.cn, bzhangnaishou@yhj.com.cn \\ ${ }^{*}$ Corresponding author
}

Keywords: Soil disturbance, soil structure, in-situ, remolded, undisturbed, compression curve.

\begin{abstract}
The soil structure, which influence the mechanical response of soil greatly, generally exists in the natural soil. During the bore drilling, transportation and soil sampling the soil sample is more or less disturbed and the compression curve changes. According to the extent of disturbance the soil sample can be divided into fully remolded soil, undisturbed soil and in-situ soil. The paper discusses the determination of compression curve of the in-situ soil from the curves of undisturbed soil and the fully remolded soil, which is quite importance for the estimation of ground settlement during design stage.
\end{abstract}

\section{Introduction}

There are plenty of soft marine soil in the east coastal area of China. General speaking, the percentage of clay particle is very large and its plasticity index is over 17. Considering the special sedimentary environment and complex composition of soft soil, the mechanical response is also very different from the usual clay due to its highly-developed structure, such as high sensitivity, low strength and easy to be disturbed.

The natural sensitive soil is easy to be disturbed. Usually, the disturbance of the soil can be classified into two categories: sample disturbance and in-situ construction disturbance. The sample disturbance includes the influence of bore drilling, stress release, sampling etc. The in-situ construction disturbance usually includes the installation of plastic vertical drains, sand compaction piles and prefabricated piles. The soil properties are greatly influenced by the soil disturbance. When the soil is disturbed, the structure yield stress is significantly reduced and the compressibility is greatly increased, which results in the additional settlement for the actual soft ground. It can be ascribed that the internal structure and stress state vary and the engineering property becomes poor due to the soil disturbance. If the ground settlement is still forecasted using the remolded or in-situ compression curve, the predicted result would be much different from the practical situation.

\section{Disturbance influence}

The influence of soil disturbance has been studied by many researchers and the review documents mainly concentrate the quantitative analysis of soil sampling disturbance and the effect on the soil compressibility[1-3]. When solving the practical problems, the soil parameters obtained by certain experiment are used. However, considering the common existence of the structure in the undisturbed soil the soil structure may vary due to the soil disturbance during bore drilling, transportation, soil sampling. Therefore, it is necessary to correct the experimental results to represent the actual properties. The deformation parameters and strength parameters are varied by the soil disturbance. Usually, the preconsolidation stress, sensitive degree, undrained strength, deformation modulus, 
consolidation coefficient of the disturbed soil would decrease while the compression index would increase. Generally speaking, the above physical and mechanical index influenced by the disturbance can be used as the evaluation index of the soil quality, such as the common comparison of undrained modulus, volume, residual effective stress and structure yield stress. But these methods are not suitable to describe the influence of soil disturbance on the compressibility which is closely related to the re-compression index, compression index, secondary consolidation coefficient and preconsolidation stress.

The influence of the soil disturbance mainly manifests that the slope of the compression curve becomes small and the consolidation coefficient also reduces. Meanwhile, the peak of the unconfined compression curve reduces significantly and the corresponding strain increases. The coefficient of the pore water pressure during the undrained compression test reduces to some extent.

\section{Determination of in-situ compression curve}

According to the practical engineering, more and more researchers have realized that there is structure strength in the natural deposited soft soil instead of some sensitive clay. Because there is more or less disturbance for the soil used in the indoor experiments, the compression curve is not so accurate. Many researchers gave the modified methods. Schmertmann[4] proposed a method to simulate the in-situ compression curve based on the compression curve of the undisturbed sample and the remolded sample. As shown in Fig. 5.1, the $e-\lg p$ compression curve is divided into two segments at the point of the structure yield stress. The determination of the structure yield stress is usually used Casagrande's method. When the overburden stress is smaller than the self-weight stress, the compression can be regarded as rigid deformation and the compression curve is a horizontal line whose void ratio equals the initial void ratio. When the overburden stress is larger than the structure yield stress, the compression curve is a line whose beginning point is the structure yield stress and ending point is the stress that corresponds to the $0.42 e_{0}$ on the compression curve of the remolded sample.

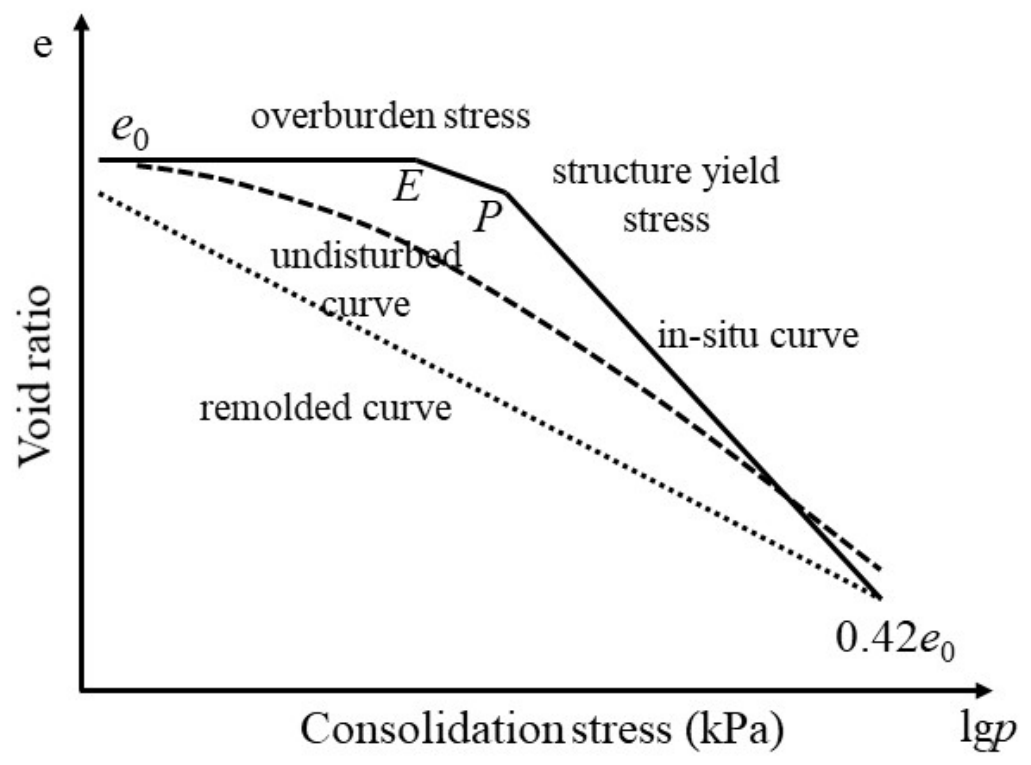

Figure 1 Determination of in-situ compression curve by Schmertmann

Nagaraj[5] believes that the in-situ compression curve should not be a straight line after the stress is over the structure yield stress. A reverse S-shape compression curve is proposed to represent the curve after the structure yield stress as shown in Fig. 2. For the zone I, the compression curve is a horizontal line which means the rigid deformation stage. For the zone II, it can be called the structure decay stage and the compression curve at this stage is simulated by power function (Eq. 1). For the zone III, it can be called the non-structural stage and the compression curve is a line that is parallel to that of the remolded soil. 


$$
e=A(\log \sigma)^{n} B
$$

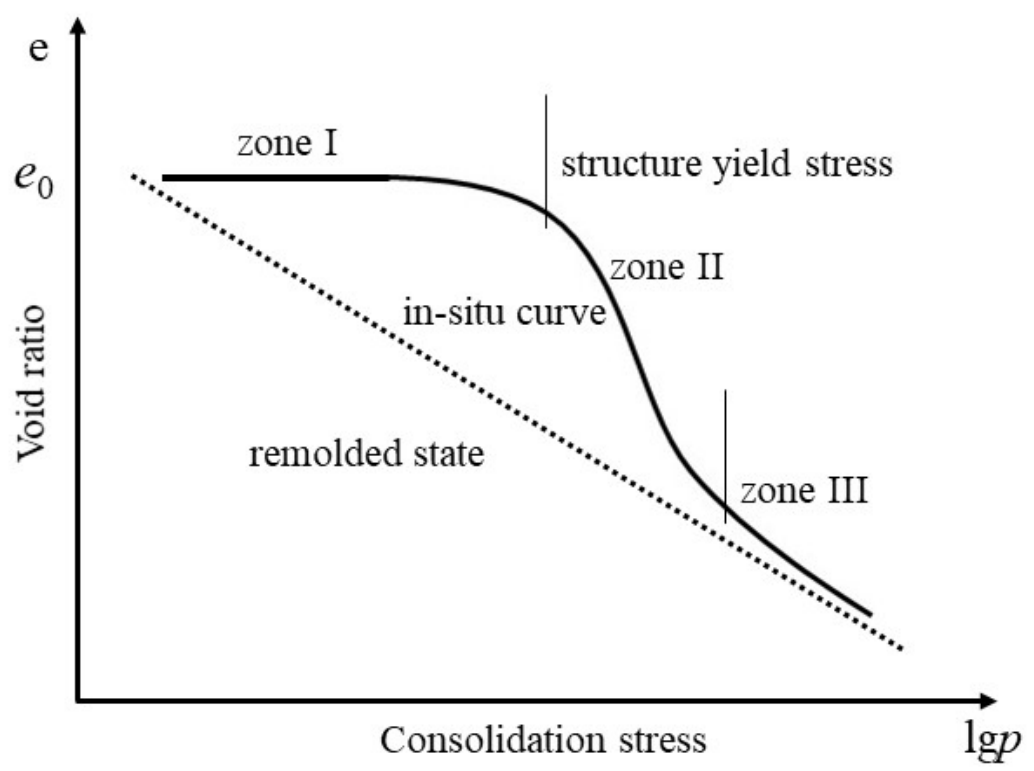

Figure 2 Typical $e-\lg p$ curve of soft clay

The structure yield stress should be determined by the cross point of the horizontal line and the compression curve with the maximum curvature. The end of the power function should be 10 times of the structure yield stress as shown in Fig. 3. The compression curve is divided into three stages to simulate the initial rigid deformation stage with cementation, structure decay after the structure yield stress and structure disappearance after the turning stress respectively.

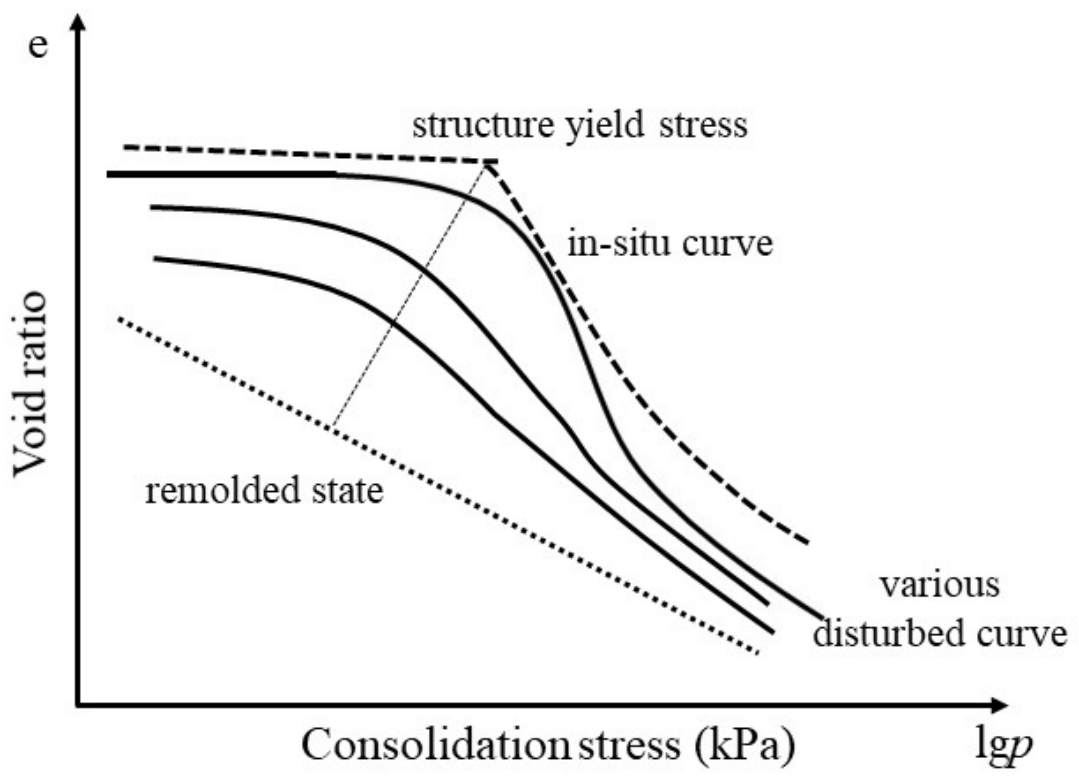

Figure 3 Determination of structure yield stress after Nagraj

\section{Evaluation of long-term settlement}

Usually the compression curve of the undisturbed sample is used to estimate the settlement of the in-situ ground based on the premise that the undisturbed sample can precisely represent the behaviour of the in-situ soil. The difference of void ratio corresponding to the vertical effective stress and additional effective stress on the $e-p$ curve is employed to estimate the ground settlement.

Due to the existence of soil structure, the compressibility of the remolded and undisturbed soil is quite different. For the aspect of engineering, if the soil structure is neglected the ability against the deformation and destroy would be underestimated. If the phenomenon of high compressibility after the structure yield stress is ignored the ability against the deformation is overestimated. Therefore, it 
is necessary to propose a simple and feasible method to evaluate the effect of structure on the long-term settlement. The sensitivity of natural soil reflects the deduction of soil strength caused by the decay of soil structure. The common measured methods include the indoor experiment, vane shear test and static cone penetration test. For the experiment, the ratio between the unconfined compression strength of undisturbed sample and remolded sample with the same water content, as shown in Eq. 2.

$$
\begin{aligned}
& S_{t}=\frac{q_{u}}{q_{0}} \\
& S_{t}=\frac{c_{u}}{c_{0}}
\end{aligned}
$$

For the vane shear test, the ratio of sensitivity is calculated by Eq. 3. In the equation, cu represents the undrained shear strength of saturated clay; $\mathrm{c} 0$ represents the undrained shear strength of remolded clay and it can be obtained by rotating six circles after the appearance of the peak strength. According to Terzaghi's classification, when the ratio of sensitivity is $4 \sim 8$ it is called high sensitive soil and when the ratio is over 8 it is called super sensitive soil. It can be assumed that the higher the sensitivity ratio is, the larger the soil structure is. Therefore, the ground with sensitivity ratio larger than 8 should be specially paid attention to.

\section{Conclusions}

When estimating the settlement of in-situ ground the compression curve is the basic tool and the accuracy of the compression curve determines the precision of the settlement. However, the in-situ compression curve is hardly to be obtained considering the soil disturbance. The paper firstly introduces the source and the influence of soil disturbance and then the common determination methods are introduced. The conclusions are as follows:

(1) The influence of the soil disturbance mainly manifests that the slope of the compression curve becomes small and the consolidation coefficient also reduces.

(2) The sensitivity ratio is closely related to the soil structure. The higher the sensitivity ratio is, the larger the soil structure is. When the highly sensitive soil is encountered, the risk of long-term settlement exists and the ground reinforcement should be carried out.

\section{References}

[1] Hight D.W. et al. Disturbance of the bothkennar clay prior to laboratory testing, Geotechnique, 42(2): 199-217.

[2] Hong Z.S. Effect of sample disturbance on mechanical properties of natural soils, Saga University, Japan, 1997.

[3] Watabe Y. Tsuchida T. Influence of stress release on sample quality of Pleistocene clay collected from large depth in Osaka Bay, Soils and Foundations, 41(4): 17-24, 2001.

[4] Schmertmann J.H. The undisturbed consolidation behavior of clay. Transaction of ASCE, 120(2): 1201-1226, 1955.

[5] Nagaraj T.S. et al. Analysis of compressibility of sensitive soils. Journal of Geotechnical Engineering, 116(1): 105-118, 1990. 